\title{
HUBUNGAN DUKUNGAN SOSIAL KELUARGA DENGAN TINGKAT KECEMASAN IBU PRIMIGRAVIDA TRIMESTER III DALAM MENGHADAPI PROSES PERSALINAN DI WILAYAH KERJA PUSKESMAS KOTA MATSUM MEDAN
}

\author{
Hendry Kiswanto Mendrofa \\ Program Studi Ilmu Keperawatan, STIKes Murni Teguh \\ E-mail : hendrykiswanto155@gmail.com
}

\begin{abstract}
Mothers who are undergoing pregnancy experience changes physically, psychologically and mentally therefore pregnant women are required not only to be physically ready, but also thirsty to be mentally prepared. Mental changes in the mother will affect the emotions of the mother. In the third trimester the psychological changes that occur include feeling anxiety and anxiety about the birth of her baby, feelings of fear of death, birth trauma and fear of birth defects. If the emotional influence of the mother is not supported by a harmonious family environment or conducive living environment, then this can cause emotional and physical disturbance (mild to severe). Preventing this from happening, then family social support for pregnant women is very important so that mothers can undergo pregnancy until the delivery process well. This type of research uses a correlation research design with the Spearman correlation test. The number of samples in the study were 30 respondents with a sampling technique that is purposive sampling. This research instrument consisted of 2 questionnaires namely a family social support questionnaire (Likert scale) and an anxiety level questionnaire (Hamilton rating scale for anxiety). The results showed that there was a relationship of family social support with anxiety levels of trimester III primigravida mothers in the face of labor, the Spearman correlation test results obtained $r$ value of 0.751 categorized as "strong" with a value of p 0.00 where p value $<0.05$. It is expected that health services and Puskesmas agencies can provide counseling / information about family social support in dealing with the delivery process so that every mother does not experience anxiety.
\end{abstract}

Keywords: Social Support, Anxiety, Pregnancy.

\section{Abstrak}

Ibu yang sedang menjalani kehamilan mengalami perubahan secara fisik, psikologis dan mental oleh karena itu ibu hamil dituntut tidak hanya harus siap secara fisik, tetapi juga haus siap secara mental. Perubahan secara mental pada ibu akan mempengaruhi emosi ibu. Pada trimester ketiga perubahan psikologis yang terjadi antara lain merasakan kegelisahan dan kekhawatiran mengenai kelahiran bayinya, perasaan takut mati, trauma kelahiran dan ketakutan bayinya lahir cacat. Apabila pengaruh emosi si ibu tidak didukung oleh lingkungan keluarga yang harmonis ataupun lingkungan tempat tinggal yang kondusif, maka hal ini dapat menimbulkan gangguan emosi dan fisik (ringan sampai berat). Mencegah hal tersebut terjadi, maka dukungan sosial keluarga untuk ibu hamil sangatlah penting agar ibu dapat menjalani kehamilan sampai proses persalinan dengan baik. Jenis penelitian ini menggunakan desain penelitian korelasi dengan uji statistik korelasi Spearman. Jumlah sampel dalam penelitian sebanyak 30 responden dengan teknik pengambilan sampel yaitu Purposive sampling. Instrumen penelitian ini terdiri dari 2 kuesioner yaitu kuesioner dukungan sosial keluarga (scale likert) dan kuesioner tingkat kecemasan (Hamilton rating scale for anxiety). Hasil penelitian menunjukkan bahwa ada hubungan dukungan sosial keluarga dengan tingkat kecemasan ibu primigravida trimester III dalam menghadapi proses persalinan, hasil uji korelasi Spearman di dapatkan nilai r 0,751 dikategorikan "kuat" dengan nilai $p 0.00$ dimana $p$ value $<0.05$. Diharapkan bagi pelayanan kesehatan dan instansi Puskesmas supaya dapat memberikan konseling/ informasi tentang dukungan sosial keluarga dalam menghadapi proses persalinan agar setiap ibu tidak mengalami kecemasan.

Kata Kunci : Dukungan Sosial, Kecemasan, Kehamilan. 


\section{PENDAHULUAN}

Pada umumnya ibu hamil trimester III yang akan menjelang persalinan akan mengalami kecemasan dan akan muncul pertanyaan bayangan apakah dapat melahirkan normal, bagaimana cara mengedan, apakah terjadi sesuatu saat melahirkan, apakah bayi lahir selamat, hal itu akan selalu muncul di dalam hati ibu hamil (Hasuki, 2010), Maramis (2010) juga menyatakan banyak calon ibu yang menghadapi proses persalinan dengan perasaan takut dan cemas.

Di Indonesia pada tahun 2008 terdapat 373.000.000 ibu hamil yang mengalami kecemasan dalam mengahadapi proses persalinan. Berdasarkan data di Pulau Jawa terdapat 67.976 ibu hamil dan yang mengalami kecemasan dalam menghadapi persalinan sebanyak 35.587 orang $(52,3 \%)$ (DepKes RI, 2008).

Dukungan sosial yang paling dekat dengan wanita hamil adalah dari pasangan (suami), Suami dapat memberikan dukungan berupa semangat dan perhatian kepada istri, membina hubungan baik dengan pasangan, mengajak jalan-jalan ringan sambil berbicara hal yang positif dan sebagainya. Dengan begitu, istri bisa kuat untuk menghadapi segala hal di masa kehamilan dan juga menjelang masa persalinan (Maharani, 2008).

Dukungan emosional yang diberikan suami terhadap istri akan memberikan ketenangan batin dan perasaan senang dalam diri istri, sehingga istri lebih mudah menyesuaikan diri dalam situasi kehamilannya (Fithriany, 2011)

\section{METODE PENELITIAN}

Penelitian ini merupakan jenis penelitian kuantitafif dengan desain penelitian korelasi. Terdapat 30 sampel dalam penelitian ini. Pengambilan sampel dengan menggunakan teknik Purposive sampling. Peneliti melakukan pengumpulan data dengan menggunakan instrument Hamilton rating scale for anxiety (HRS-A) dan dukungan sosial keluarga. Untuk mengetahui ada tidaknya hubungan dengan menggunakan uji statistik non parametrik yaitu korelasi Spearman dengan asumsi jika nilai $p<0,05$ maka dapat disimpulkan terdapat korelasi yang signifikan antara variabel yang dihubungkan atau sebaliknya serta menafsirkan kekuatan hubungan antara variabel dengan berpedoman pada tabel koefisien korelasi.

\section{HASIL PENELITIAN}

1. Karakteristik Responden

Tabel 1. Karakteristik Ibu Hamil Yang dalam Menghadapi Proses Persalinan di Wilayah Kerja Puskesmas Kota Matsum Medan ( $\mathrm{n}=30)$

\begin{tabular}{clcc}
\hline No. & \multicolumn{1}{c}{ Karakteristik } & $f$ & $\%$ \\
\hline 1 & Usia & & \\
& $<20$ & 3 & 10 \\
& $21-30$ & 22 & 73.3 \\
& $>30$ & 5 & 16.7 \\
2 & Pendidikan & & \\
& SD & 2 & 6.7 \\
& SMP & 4 & 13.3 \\
& SMA & 13 & 43.3 \\
& PT & 11 & 36.7 \\
Pekerjaan & & \\
& IRT & 19 & 63.3 \\
& Wiraswasta & 5 & 16.7 \\
& PNS & 1 & 3.3 \\
& Lainnya & 5 & 16.7 \\
Suku & & \\
Batak & 7 & 23.3 \\
& Jawa & 11 & 36.7 \\
& Lainnya & 12 & 40 \\
Agama & & \\
& Islam & 27 & 90 \\
Kristen & 3 & 10 \\
\hline
\end{tabular}

Berdasarkan tabel 1 diatas menunjukkan bahwa mayoritas responden memiliki usia dari 21-30 Tahun sebesar 73.3 $\%$, berdasarkan tingkat pendidikan mayoritas responden berpendidikan SMA sebesar $43.3 \%$, berdasarkan pekerjaan mayoritas responden ibu rumah tangga sebesar $63.3 \%$, berdasarkan suku mayoritas bersuku jawa sebesar $36.7 \%$, dan mayoritas responden beragama Islam sebesar $90 \%$. 
2. Dukungan Sosial Keluarga Dalam Menghadapi Proses Persalinan

Tabel 2. Distribusi Frekuensi Dukungan Sosial Keluarga dalam Menghadapi Proses Persalinandi Wilayah Kerja Puskesmas Kota Matsum Medan (n:30)

\begin{tabular}{clcc}
\hline No. & $\begin{array}{c}\text { Dukungan Sosial } \\
\text { Keluarga }\end{array}$ & $f$ & $\%$ \\
\hline 1. & Baik & 25 & 83.3 \\
2. & Cukup & 5 & 16.7 \\
3. & Kurang & - & - \\
\hline & Jumlah & 30 & 100 \\
\hline
\end{tabular}

Berdasarkan hasil penelitian yang disajikan dari tabel diatas menunjukkan bahwa dukungan sosial keluarga yang baik sebanyak 25 (83.3\%), dan minoritas dukungan keluarga yang cukup sebanyak 5 $(16.7 \%)$.

\section{Tingkat Kecemasan Dalam Menghadapi Proses Persalinan Tabel 3.}

Distribusi Frekuensi Tingkat Kecemasan Ibu Primigravida Trimester III dalam Menghadapi Proses Persalinan diWilayah Kerja Puskesmas Kota Matsum Medan (n:30).

\begin{tabular}{clcc}
\hline No & Kualitas Asuhan & $f$ & $\%$ \\
\hline 1. & Tidak ada & 11 & 36.7 \\
& Kecemasan & & \\
2. & Kecemasan Ringan & 2 & 6.7 \\
3 & Kecemasan sedang & 3 & 10 \\
4 & Kecemasan Berat & 14 & 46.7 \\
5 & Kecemasan Panik & - & \\
\hline & $\quad$ Jumlah & 30 & 100 \\
\hline
\end{tabular}

Berdasarkan hasil penelitian yang disajikan pada tabel diatas menunjukkan bahwa yang mayoritas tingkat kecemasan ibu berada pada kategori berat yaitu sebanyak 14 orang (46.7\%), dan minoritas tingkat kecemasan ibu berada pada kategori ringan sebanyak 2 orang $(6.7 \%)$.

\section{Hubungan Dukungan Sosial Keluarga Dengan Tingkat Kecemasan Ibu}

Primigravida Trimester III Dalam Menghadapi Proses Persalinan

Tabel 4. Hasil Uji Korelasi Spearman Dukungan Sosial Keluarga dengan Tingkat Kecemasan Ibu Primigravida Trimester III dalam Menghadapi Proses Persalinan di Wilayah Kerja Puskesmas Kota Matsum Medan

\begin{tabular}{|c|c|c|c|}
\hline & \multicolumn{2}{|c|}{$\begin{array}{c}\text { Tingkat } \\
\text { Kecemasan }\end{array}$} & \multirow[t]{2}{*}{ Keterangan } \\
\hline & $r$ & $p$ & \\
\hline $\begin{array}{l}\text { Dukungan } \\
\text { Sosial } \\
\text { Keluarga }\end{array}$ & 0.751 & 0,00 & $\begin{array}{l}\text { Ada hubungan yang } \\
\text { signifikan antara } \\
\text { kedua variabel, } \\
\text { kekuatan hubungan } \\
\text { berada pada kategori } \\
\text { "kuat". }\end{array}$ \\
\hline
\end{tabular}

Berdasarkan tabel diatas didapatkan nilai $r$ sebesar 0,751 yang menunjukkan bahwa kekuatan hubungan dukungan sosial keluarga dengan tingkat kecemasan ibu primigravida trimester III dalam menghadapi proses persalinan di kategorikan "kuat" dengan nilai $p 0.00<$ 0.05. hal ini menjelaskan bahwa Ho ditolak dan Ha diterima sehingga disimpulkan ada hubungan yang signifikan antara kedua variabel

\section{PEMBAHASAN.}

Dukungan Sosial Keluarga Pada Ibu Primigravida Dalam Menghadapi Proses Persalinan.

Berdasarkan hasil penelitian yang dilakukan kepada 30 resonden pada ibu hamil primigravida trimester III dalam menghadapi proses persalinandi wilayah kerja Puskesmas Kota Matsum Medan Tahun 2017, hasil menunjukkan bahwa mayoritas memiliki dukungan sosial keluarga yang baik sebanyak 25 orang $(83,3 \%)$ dan minoritas dukungan sosial keluarga cukup sebanyak 5 orang $(16,7 \%)$.

Menurut Purwoastuti \& Walyani (2015) dukungan keluarga merupakan bantuan atau dukungan yang diterima individu dari seseorang dalam kehidupannya 
dan berada dalam lingkungan keluarga seperti suami, orangtua, mertua, yang membuat penerima merasa diperhatikan, dihargai dan dicintai sedangkan untuk orang yang menerima dukungan keluarga memahami makna dukungan diberikan oleh keluarga.

Dukungan keluarga secara emosional adalah faktor penting untuk keberhasilah tugas perkembangan dalam proses persalinan seorang wanita yang memiliki hubungan harmonis dengan keluarganya akan mengalami pengaruh emosi dan gejala fisik lebih sedikit termasuk komplikasi ketika melahirkan dan menyesuaikan diri pasca partum (Asnawir, 2015)

\section{Kecemasan Pada IbuPrimigravida Trimester III Dalam Menghadapi Proses Persalinan.}

Hasil penelitian menunjukkan bahwa tingkat kecemasan pada Ibu primigravida trimester III dalam menghadapi proses persalinan diWilayah Kerja Puskesmas Kota Matsum Medan Tahun 2017, hasil menunjukkan bahwa mayoritas mengalami kecemasan berat sebanyak 14 orang $(46.7 \%)$, ibu yang tidak mengalami kecemasan sebanyak 11 orang (36.7\%), ibu yang mengalami kecemasan sedang sebanyak 3 orang $(10.0 \%)$ danminoritas ibu yang mengalami kecemasan ringan sebanyak 2 orang $(6.7 \%)$.

Faktor-faktor yang menjadi timbulnya kecemasan biasanya berubungan dengan kondisi kesejahteraan ibu dan bayi yang akan dilahirkan, pengalaman keguguran, rasa aman dan nyaman selama masa kehamilan, penemuan jati dirinya dan persiapan menjadi orang tua, sikap memberi dan menerima kehamilan, dukungan keluarga, suport tenaga medis, usia ibu hamil, tingkat persiapan ibu, pengalaman traumatis dan tingkat aktifitas ibu (Janiwarty \& Pieter, 2013).

Hubungan Dukungan Sosial Keluarga
Dengan Tingkat Kecemasan Pada Ibu
Primigravida Trimester III Dalam
Menghadapi Proses Persalinan Di
Wilayah Kerja Puskesmas Kota Matsum Berdasarkan hasil uji non parametrik korelasi Spearman didapatkan nilair sebesar 0,751 yang menunjukkan bahwa kekuatan hubungan antar dukungan sosial keluarga dengan tingkat kecemasan ibu primigravida trimester III dalam menghadapi proses persalinan dikategorikan "kuat" dengan nilai $P 0.00$ $<0.05$ berarti Ha diterima. Hal ini secara statistik menunjukkan adanya hubungan yang signifikan antara dukungan sosial keluarga dengan tingkat kecemasan ibu primigravida trimester III dalam menghadapi proses persalinan.

Merujuk pada teori Buffering Hypothesis yang berpandangan bahwa dukungan sosial mempengaruhi kesehatan dengan cara individu mampu menghadapi dari efek negatif stress maupun kecemasan. Perlindu ngan ini akan efektif hanya ketika individu menghadapi stres. Dukungan sosial yang diberikan pada wanita hamil dapat menumbuhkan perasaan tenang, aman, dan nyaman sehingga dapat mempengaruhi kecemasan ibu hamil. Dengan demikian dukungan keluarga sangat diharapkan oleh ibu hamil dalam menghadapi proses persalinan agar dapat mengurangi tingkat kecemasan ibu dan proses persalinan lancar (Aprinawati \& Sulistyorini, 2007).

Faktor yang mempengaruhi kecemasan pada ibu hamil yaitu status kesehatan ibu dan bayi, umur, pendidikan, pekerjaan, ekonomi, dan dukungan keluarga khususnya suami (Stuart, 2008). Hasil penelitian Tursilowati dan Sulistyorini (2008) dapat menunjukkan beberapa peran penting suami dalam menghadapi proses persalinan yaitu mempersiapkan dana yang ekstra, memberi waktu yang luang untuk selalu bersama dengan ibu hamil dan dapat membuat perjalanan kehamilan ibu semakin lancar dan aman sehingga proses persalinan mudah.

Hasil penelitian yang dilakukan Sulistyorini, (2007) menunjukkan bahwa dukungan yaitu cukup 8 responden $(29,6 \%)$, dan dukungan keluarga baik 19 
responden (70,4\%). Hasil tingkat kecemasan pada ibu hamil menunjukkan bahwa ibu hamil yang memiliki kecemasan ringan yaitu sebanyak $17 \mathrm{ibu}$ hamil $(63,0 \%)$, dan yang mengalami kecemasan sedang sebanyak 6 ibu hamil $(22,2 \%)$ sehingga hasil penelitian menunjukkan nilai $p$-value $0,001<0,005$ berarti ada hubungan antara dukungan keluarga dengan tingkat kecemasan ibu hamil.

Berdasarkan hasil penelitian Stiarti (2011) yang berjudul hubungan dukungan suami dengan tingkat kecemasan ibu hamil primigravida trimester III di RSUD Temanggung bahwa dukungan keluarga dengan kategori sedang 16 orang $(48,5 \%)$, tingkat kecemasan ibu hamil primigravida dengan kategori sedang 14 orang $(37,1 \%)$ sedangkan yang mengalami kecemasan berat 7 orang $(8,6 \%)$. Hasil uji statistik ini didapatkan nilai 0,587 dengan signifikan 0,00 . Maka dapat hasil kesimpulan bahwa ada hubungan antara dukungan sosial dengan tingkat kecemasan ibu primigravida trimester III.

Berdasarkan hasil penelitian Reska Handayani (2010) yang berjudul hubungan dukungan keluarga dengan tingkat kecemasan menjelang persalinan pada ibu primigravida trimester III di Wilayah Kerja Puskesmas Lubuk Buaya Padan Tahun 2012 dengan hasil menunjukkan bahwa nilai $\mathrm{p}$ value $0,00(\mathrm{p}<0,05)$ terdapat hubungan yang bermakna antara dukungan keluarga dengan tingkat kecemasan ibu menjelang persalinan.

\section{KESIMPULAN}

Berdasarkan hasil penelitian tentang Hubungan Dukungan Sosial Keluarga Dengan Tingkat Kecemasan Ibu Primigravida Trimester III dalam Menghadapi Proses Persalinan di Wilayah Kerja Puskemas Kota Matsum Medan, maka dapat disimpulkan sebagai berikut:

1. Hasil menunjukkan bahwa ibu hamil yang mayoritas memiliki dukungan sosial keluarga yang baik sebanyak 25 orang $(83,3 \%)$ di wilayah kerja Puskesmas Kota Matsum Medan.
2. Hasil menunjukkan bahwa Ibu hamil yang mayoritas mengalami kecemasan berat sebanyak 14 orang (46.7\%) di wilayah kerja Puskesmas Kota Matsum Medan.

3. Ada Hubungan Dukungan Sosial Keluarga Dengan Tingkat Kecemasan Ibu Primigravida Trimester III dalam Menghadapi Proses Persalinan di Puskemas Kota Matsum Medan, dengan hasil uji Spearman dimana pvalue $<0.05$.

\section{SARAN}

Berdasarkan analisis dan pembahasan hasil penelitian, disarankan untuk bagi responden selama kehamilan ibu hamil memperluas wawasan mengenai tentang persiapan dan proses persalinan dan pentingnya dukungan sosial keluarga terhadap kehamilan ibu. agar ibu hamil merasa tenang, senang dan nyaman sehingga ibu siap untuk menghadapi proses persalinannya

\section{DAFTAR PUSTAKA}

Aprianawati, R. B. \& Sulistyorini, I. R. 2007. Hubungan antara dukungan keluarga dengan kecemasan ibu hamil menghadapi kelahiran anak pertama pada masa triwulan ketiga. Psikologi.

Asnawir, (2015) Hubungan Dukungan Sosial Keluarga Dengan Kecemasan Ibu Hamil Menghadapi Proses Persalinan Di Puskesmas Budilatama Kecamatan Gadung Kabupaten Buol Provinsi Sulawesi Tengah. Jurnal Keperawatan. Vol. 3.

Fithriany. (2011). Pengaruh Karakteristik Ibu Dan Dukungan Suami Terhadap Pemeriksaan Kehamilan Di Kecamatan Kuta Cot Gile Kabupaten Aceh Besar. Tesis: Fakultas Keperawatan Universitas Sumatra Utara.

Handayani. 2012. Berhubungan Dengan Tingkat Kecemasan Menjelang Persalinan Pada Ibu Primigravida Trimester III Di Wilayah Kerja 
Puskesmas Lubuk Buaya Padang. Jurnal Keperawatan. Vol 11, No 1.

Hasuki, L. 2010. Buku Saku Keperawatan Kesehatan Ibu dan Anak. Jakarta: EGC

Janiwarty \& Pieter. 2013. Pendidikan Psikologi Untuk Bidan. Yogyakarta: Rapha Publishing.

Maharani TI. 2008. Hubungan Antara Dukungan Sosial Dan Kecemasan Dalam Menghadapi Persalinan Pada Ibu Hami Trimester Ketiga. Skripsi. Jawa Barat: Jurnal Fakultas Psikologi.

Maramis. 2009. Catatan Ilmu Kedokteran Jiwa. Edisi 2. Surabaya: Airlangga.

Stiarti D. 2011. Hubungan Dukungan Suami Dengan Tingkat Kecemasan Ibu Hamil Primigravida Trimester III. Y ogyakarta: Program Studi Ilmu Kepe rawatan.

Stuart, \& Sundeen. (2008). Buku Saku Keperawatan Jiwa Edisi 4. Jakarta: EGC.

Purwoastuti \& Walyani. 2015. Ilmu Kesehatan Masyarakap Dalam Kebidanan. Yogyakarta: Pustaka baru press.

Tursilowati dan Sulistyorini. (2007). Pengaruh Peran Serta Suami Terhadap Tingkat Kecemasan Ibu Hamil Dalam Menghadapi Proses Persalinan. Yogyakarta: Jurnal Kesehatan Surya Medika. 